\title{
Effect of financial inclusion on entrepreneurial growth in retail and wholesale sub-sectors: Evidence from Nigeria
}

\author{
Anisiuba Chika Anastesia \\ Department of Accountancy \\ University of Nigeria, Enugu Campus, Nigeria \\ Ezeaku Hillary Chijindu \\ Department of Banking and Finance \\ Caritas University, Enugu, Nigeria \\ Emengini Emeka Steve \\ Department of Accountancy \\ University of Nigeria, Enugu Campus, Nigeria
}

\section{Keywords}

Entrepreneurial growth (EG), financial inclusion (FI), retail sub-sector, wholesale sub-sector

\begin{abstract}
Financial inclusion has been globally recognised as essential for capital accumulation, easy financial services accessibility, poverty alleviation as well as entrepreneurial and economic growth. As Nigerian government is making progress in the achievement of financial inclusion, many businesses seems to be springing up in the financial and other economic sectors with intention to tap from the growing access to official financial services. This paper aims at ascertaining the effect of financial inclusion (FI) on entrepreneurial growth (EG) in retail and wholesale sub-sectors in Nigeria using quarterly data from the World Bank's World Development Indicators and the Central Bank of Nigeria. Data were analysed using correlation analysis and error correction approach. The results reveal that FI has a significant positive effect on EG particularly in the context of the retail and the wholesale subsectors contributions to gross domestic product (GDP). The results further indicate that account ownership (ACN) did not have significant influence on the growth rate of the retail and the wholesale sub-sectors, while commercial bank branches (CMB) was found to have significant influence on the growth rate of the retail and the wholesale sub-sectors. This implies that CMB is a critical FI channel with potentials of driving the EG particularly in the context of the retail and the wholesale sub-sectors contributions to GDP. We recommend that government should establish more CMB in all rural areas in Nigeria for easy access to official financial products by the unbanked entrepreneurs. Also, FI stakeholders should deepen efforts in encouraging ACN through improving on financial literacy of the vast unbanked populace so that formal financial system through capital accumulation can serve the needs of entrepreneurs for effective growth and contributions to GDP.
\end{abstract}

\section{Acknowledgement}

The authors duly appreciate World Bank and the Central Bank of Nigeria for making data used for this study possible.

\section{Introduction}

In recent times, FI has become a crucial economic strategy for the achievement of national economic growth and sustainability in both developed and developing economies. The positive effects of FI on economic growth are mostly seen in developed countries like United States, United Kingdom, Germany, China and Japan where FI rate is very high compared with developing countries like Nigeria where FI rate is very low (Nkwede, 2015). The low rate of FI in Nigeria is buttressed by the result of a survey carried out by Enhancing Financial Innovation and Access (EFInA) in 2008 which revealed that more than half of the adult population are excluded from financial services (Arogundade, 2019). To handle the situation, Nigerian government established commercial banks and community banks thereby bringing financial services nearer to the vulnerable and unbanked citizens. Through the extension of the financial services, financial exclusion rate dropped from 53 per cent to 46.3 per cent by 2010 . Spurred by this 
development, the Central Bank of Nigeria (CBN) and major FI stakeholders initiated the National Financial Inclusion Strategy (NFIS) to reduce the exclusion rate to 20 per cent by 2020 (Arogundade, 2019).

Relatively, the FI rate achieved so far in Nigeria is expected to have effect on the entrepreneurial and economic growth rate which seems to be insignificant considering the dwindling economic activities in the country. This expectation is based on the general consensus that FI of the vulnerable and unbanked population in a country will lead to capital accumulation, business and economic growth. Beyond this, it is discovered that the effect of FI on EG in retail and wholesale sub-sectors in Nigeria has not received the desired empirical study. The fewness of literature in this area leaves little to be desired since government, $\mathrm{CBN}$, economic development experts, financial institutions and other stakeholders would find the research result(s) extremely useful in making economic decisions. Also, entrepreneurs who are the unit analysis of this study are the backbone of economic growth through their contribution to GDP, job creation and value-added functions. It is against these backgrounds that this study aims at ascertaining the effect of FI on EG in retail and wholesale sub-sectors in Nigeria. Unlike most existing studies, which relied on micro level data, this paper exploits macro level data by using quarterly dataset for the period 2010: Q1 - 2016: Q4 which were available. The data were obtained from the World Bank's World Development Indicators and the Central bank of Nigeria. In this study, we utilized the retail and the wholesale sub-sectors contributions to GDP as a measure of entrepreneurial growth.

\section{Literature review}

\subsection{Overview of financial inclusion (FI)}

Financial inclusion is the process of extending financial products to the unbanked and vulnerable populace. This process enables individuals and businesses to have access to financial services such as deposit, loans, insurance, payments and fund transfer at their convenience and to meet economic needs. In other words, it is the bringing home of financial services at an affordable cost to the disadvantage group in the society, especially the low-income and underprivileged (Gwalani \& Parkhi, 2014).

Generally, FI is an essential means to an end and not an end in itself. It has been revealed to be a means to achieving financial services accessibility, capital accumulation, poverty alleviation, increasing savings and investments, greater financial stability as well as entrepreneurial and economic growth in both developed and developing countries (Terzi, 2015; Onaolapo, 2015). Beck and Demirguc-Kunt's study, conducted in 2006 (as cited in Lakuma, Marty, \& Muhumuza, 2019) also pointed out the importance of FI by saying that it helps to alleviate enterprises' growth constraints and increases their access to finance thus leveling the playing field between firms of different sizes. Specifically, FI connects and avail people the opportunity to interact with banks which yield social and economic benefits both to the individual and the nation. Chong and Chan's study, conducted in 2010 (as cited in Kama \& Adigun, 2013) also emphasized that access to a well-functioning financial system through creation of equal opportunities enables socially and economically excluded people to integrate into the economy and actively contribute to economic growth.

\subsection{Financial inclusion in Nigeria}

Prior to the recent efforts to increase the FI rate in Nigeria, the economy was largely cash based. This made the issue of financial inclusion a major economic challenge that attracted the attention of government over the past four decades (Kama \& Adigun, 2013). Among the major government efforts which aimed at promoting FI was the establishment of commercial banks in rural areas of the country, interventionist financing arrangements and building of institutions and frameworks that promotes FI.

Recently, government took critical initiative by incorporating FI as one of the cardinal objectives of the Nigerian Financial System Strategy 2020 (FSS 2020). The FSS 2020 represents a holistic and strategic road map and framework for developing the Nigerian financial sector into a growth catalyst that will enable Nigeria to be one of the 20 largest economies by 2020 (Kama \& Adigun, 2013). The strategy identified six stakeholders (regarded as the suppliers in the value chain of FI) namely banking institutions, non-bank financial institutions, insurance companies, capital market players, pension institutions and technology providers together with their regulatory bodies. The determination of the government to expand FI in Nigeria is clearly shown in the six initiatives adopted to strengthen the domestic financial market in which four initiatives directly addressed FI. The four initiatives are development of varied 
financial products, enhancement of payment processes, development of credit system and encouragement of a savings culture. The aim of the government initiatives is to achieve a state in which adults above the age of 18 have formal easy access to a broad range of financial products which are appropriate, provided at affordable cost and with dignity of the citizens.

According to Arogundade (2019) the implementation of FI strategy has brought about a decline in financial exclusion in Nigeria, thereby improving FI rate over the past years. He reported that the 2018 survey of the Nigerian financial system carried out by EFInA recorded a major boost in FI rate when compared with previous years' rate. The survey showed that the number of people who currently have access to financial services has increased to 63.6 per cent while only 36.4 per cent are financially excluded compared with 46.3 per cent of exclusion in 2010. The indicators upon which the survey was conducted include banked population, savings, remittances, payments, loans and banking agents. According to the survey, digital payments increased tremendously. An increase from 5,000 monthly volumes in 2011 to 30 million in 2018 is made visible in the quantity of card transactions on POS as reported by the director of Nigeria Inter-Bank Settlement System. There has also been an increase in the quantity of installed POS terminals from 10,000 in 2011 to 200,000 in 2018 - an indication that the measures and initiatives put in place were productive.

\subsection{Financial inclusion (FI) and entrepreneurial growth (EG)}

Entrepreneurs are globally recognised as the engine of economic development and growth through their value-added functions. According to Ageme, Anisiuba, Alio, Ezeaku and Onwumere (2018) access to financial services offers entrepreneurs and real sector business owners the opportunity to grow their businesses, manage, mitigate risk, sustain and be able to absorb financial shocks. It also offers them the opportunity to make daily payments reliably, access credit conveniently, save cash for unforeseeable risks or future investment and also achieve insurance in a sustainable way. Moreover, availability of financial services fosters the achievement of economic functions such as contribution to GDP, utilization of unused raw materials and human resources, employment creation, meeting of local needs, stimulation of business competition and economic growth/sustainability (Terzi, 2015; Riwayati, 2017).

\subsection{Retail and wholesale sub-sectors in Nigeria}

Retail refers to the sale of goods or services directly to the end-users in small quantity. According to Sarker and Ashrafi (2018) a retail store offers a wide range of necessity goods for household and daily living. In Nigeria, retail stores are mostly patronized by unbanked population and the industry controls a large percentage of the total trading sector. Based on research findings, Oluwaseun (2017) revealed that the unbanked population control about $70 \%$ of daily retail transaction resulting to the increasing number of informal financial operators whose activities are not regulated, and high volume of liquidity which could have been used to create economic opportunities if deposited in formal financial institution. The percentage distributions of retail sub-sector transactions in Nigeria are presented in table 1.

\begin{tabular}{|c|l|}
\hline Percentage & Transaction Analysis \\
\hline $5 \%$ & $\begin{array}{l}\text {-Early transaction Services (12am - Sam) } \\
\text {-Typically use ATM and Internet Banking } \\
\text {-Value tied down in commodities for trade }\end{array}$ \\
\hline $25 \%$ & $\begin{array}{l}\text {-Typical Banking Hour (8am - 4pm) } \\
\text {-Supported by all Banking Services } \\
\text {-Limited to Branch presence and Internet }\end{array}$ \\
\hline $70 \%$ & $\begin{array}{l}\text {-Typical Cash Transaction (4pm - 12am) } \\
\text {-Dominated by Non-Financial and Unbanked } \\
\\
\text {-Alternative Banking Services Holds 5\% }\end{array}$ \\
\hline
\end{tabular}

Table 1 Retail Transaction Analysis

Source: Adapted from Oluwaseun, 2017

The retail transaction analysis showed the financial exclusion level which the government FI strategy is greatly aiming to address.

On the other hand, wholesale refers to the sale of goods or services in bulk directly to retailers and other outlets who are not the end users. Wholesalers deal on different kinds of product such as household, 
technology driven products/materials, telephone accessories, electrical and office materials. They engage in B2B (business to business) sales. Wholesalers mostly create easy-to-pay-invoices that include customer purchase order (PO) numbers or billing codes, list of goods and prices as well as payment terms (Scott, 2019). However, access to financial services such as online fund transfer, bank credit and insurance among others occasioned by FI target has simplified finance and payment processes which made growth in wholesale business easier.

\subsection{Theoretical review}

According to Okoye, Adetiloye, Erin and Modebe (2017) the relationship between finance and real activity can be traced to Smith in 1776 who argued that the real growth in an economy is driven by the activities of the financial sector based on the fact that increased production and specialization are facilitated by enhanced credit resource acquisition offered by the financial system. Okoye, et al. (2017) also pointed out that Schumpeter in 1912 avers that technological innovation (a prerequisite for productivity growth) is facilitated by financial sector through efficient resource accumulation, mobilization and allocation. In other words, financial sector is vital for a successful entrepreneurial engagement in technological innovation because translating innovative thinking into real output has cost implications which may not be covered by entrepreneurs themselves (Homaid, Minai, \& Al-Ansi, 2018).

\subsection{Empirical review}

In studying FI across Africa, Demirguc-Kunt and Klapper (2012) examined the use of financial services by small and medium enterprises (SMEs) in Africa compared with SMEs in other developing regions in terms of account ownership and availability of lines of credit. The study revealed that less than a quarter of adults in Africa have an account with a formal financial institution. Also, many adults in Africa use informal methods to save and borrow. Moreover, majority of SMEs in Africa are unbanked, and access to finance is a major business obstacle. Compared with other developing economies, highgrowth SMEs in Africa are less likely to use formal financing which suggests that formal financial systems are not serving the needs of enterprises with growth opportunities.

Salman, Ayo-Oyebiyi and Emenike (2015) examined the effect of FI on SMEs growth and economic development in Nigeria by looking into three dimensions - mobile banking, banking services and banking penetration. The research outcome showed that FI with the three dimensions studied has a significant positive effect on the growth and development of SMEs in Nigeria. Using Partial least square program as data processing tool, Riwayati (2017) analyzed the success of SMEs that are mediated by FI of business players and the role of FI in increasing the success of SMEs in Indonesia. Questionnaires were distributed to 76 stone craftsmen. The study showed that human resources, finance, production, government policy, economic and the role of related institutions have significant positive effect on the success of SMEs of stone craftsmen in Magelang Regency, Indonesia.

Babajide, Adegboye and Omankhanlen (2015) studied the impact of FI on economic growth in Nigeria. In this study, they utilized secondary data which were sourced from world development indicators and used ordinary least square regression model for data analysis. The study showed that FI is a significant determinant of the total factors of production as well as capital per worker which invariably determines the final level of output in the economy. They also pointed out that FI generated savings which increased productive investments in local businesses. Ibor, Offiong and Mendie (2017) studied the impact of FI on the micro, small and medium enterprises (MSMEs) performance in Nigeria. They used questionnaire to collect data from the respondents which were analyzed using Pearson Chi-square technique. The result showed that whereas FI positively and significantly impacts on the operations and growth of MSMEs, lack of nearness to the financial services access points and infrastructural deficiency challenged fast and effective access to financial services by MSMEs in Nigeria.

Jiang, Tong, Hu and Wang (2019) carried out empirical analysis of the impact of China's inclusive financial inclusion development index on farmers' entrepreneurship using static panel and dynamic panel estimation method. The result showed that there are certain differences in inclusive financial inclusion development level in various provinces in China. They pointed out that farmers' entrepreneurship can be promoted by improving the inclusion development level of inclusive finance. Nkwede (2015) investigated the influence of FI on the growth of African economies using Nigeria as a case study. Extrapolated time 
series FI data from Nigeria covering the period of 1981 to 2013 were used for the analysis. The multiple regression models anchored on Ordinary Least Square technique was adopted in estimating the contributions of the variables. The results showed that FI has significant negative impact on the growth of Nigerian economy over the years. The researcher attributed the result to high level of financial exclusion of bankable adult citizens in Nigeria in particular and Africa in general. It was suggested that more inclusive financial system in Nigeria (and Africa) with focus on the rural populace should be embarked on especially in the developing economy.

\section{Research methodology}

This study analyzed the effect of FI on entrepreneurial growth in Nigeria using quarterly dataset for the period 2010: Q1 - 2016: Q4 which were obtained from the Central Bank of Nigeria (CBN) Statistical Bulletin, 2018. The data for the response variables are represented by growth rates of the retail and the wholesale sub-sectors contributions to GDP. The independent variables/proxies for FI comprise account ownership in a financial institution $(\mathrm{ACN})$ or with a mobile-money-service provider (\% of population ages 15 and above) and commercial bank branches (CMB) per 100,000 adults which were collated from the World Bank's World Development Indicators (WDI).

Data obtained is estimated using the error correction model (ECM) technique. The choice of the model is based on the fact that the variables under study attained stationarity at order one (i.e. I (1)). This entails that the series are integrated at the same other and are potentially cointegrated. The use of ECM will not only enable the ascertainment of the degree and magnitude of influence of FI on the response variables of interest but will also guide in determining the speed of adjustment towards a long-run equilibrium relationship.

\subsection{Model specification}

Two models where proposed for this study which analyzed the effect of FI on EG. FI is measured by the ACN and $\mathrm{CMB}$ while EG is measured by the growth rate of the retail sub-sector (RTGR) and the growth rate of the wholesale sub-sector (WSGR) contributions to GDP. The baseline models for the study are expressed in the following form:

$$
\begin{aligned}
& R T G R_{t}=\beta_{0}+\beta_{1} A C N_{t}+\beta_{2} C M B_{t}+\varepsilon_{t}------(1) \\
& W S G R_{t}=\beta_{0}+\beta_{1} A C N_{t}+\beta_{2} C M B_{t}+\varepsilon_{t}--------(2)
\end{aligned}
$$

Where:

$\begin{array}{lll}\text { RTGR } & = & \text { Growth rate of Retail Sub-sector } \\ \text { WSGR } & = & \text { Growth rate of Wholesale Sub-sector } \\ \mathrm{ACN} & = & \text { Account ownership in a financial institution }(\% \text { of population ages 15+) } \\ \mathrm{CMB} & = & \text { Commercial bank branches (per 100,000 adults) } \\ \varepsilon & = & \text { Error term } \\ \beta_{0} & = & \text { intercept } \\ \beta_{1-} \beta_{2} & = & \text { coefficient of the independent variables }\end{array}$

\section{Findings/results 4.1 Descriptive statistics}

\begin{tabular}{lcccc}
\hline & CAN & CMB & RTGR & WSGR \\
\cline { 2 - 5 } Mean & 37.49966 & 5.714446 & 1.311323 & 1.294451 \\
Median & 41.13749 & 5.813443 & 1.782977 & 1.835635 \\
Maximum & 44.74671 & 6.560718 & 7.388445 & 7.019415 \\
Minimum & 23.96382 & 4.739802 & -6.173594 & -5.929956 \\
Std. Dev. & 7.594916 & 0.637465 & 3.892044 & 3.693827 \\
Observations & 28 & 28 & 27 & 27 \\
\hline
\end{tabular}

Table 2. Descriptive Summary

Summary statistics in table 2 reveals that on average about $37.50 \%$ of the Nigerian population ages 15 and above owned account in a financial institution or with a mobile-money-service provider. Also, 
there was approximately an average of 6 bank branches per 100,000 adults. Whereas the maximum bank branches per 100,000 adults was approximately 7, the maximum percentage of population (15+) who operated an account in a financial institution was $44.75 \%$ within the coverage period. We further observed that quarterly contributions of the retail and the wholesale sub-sectors to GDP grew at an average rate of $1.31 \%$ and $1.29 \%$ respectively.
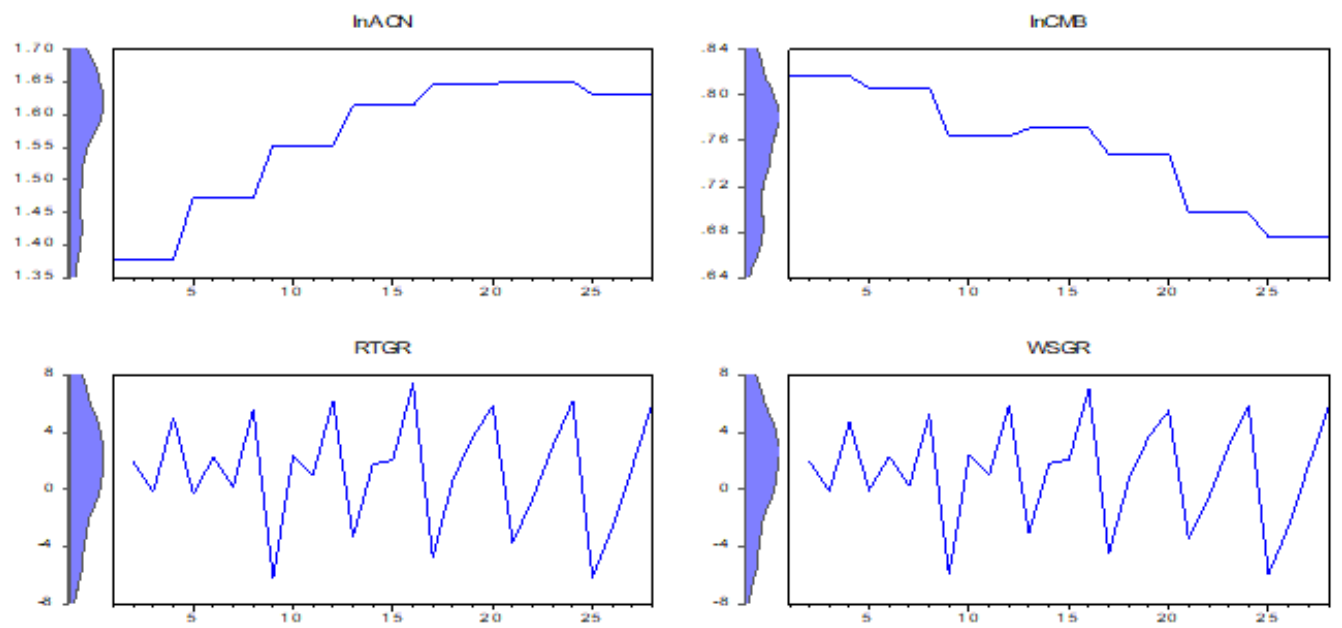

Figure 1. Graphical Description of Variable proxies

\subsection{Stationarity test}

\begin{tabular}{ccccc}
\hline Variable & ADF-Statistic & $\begin{array}{c}5 \% \text { critical } \\
\text { value }\end{array}$ & P-value & $\begin{array}{c}\text { Order of } \\
\text { Integration }\end{array}$ \\
\hline RTGR & -5.164417 & -3.673616 & 0.0030 & $\mathrm{I}(1)$ \\
\hline WSGR & -5.159453 & -3.673616 & 0.0030 & $\mathrm{I}(1)$ \\
\hline CAN & -3.968919 & -3.658446 & 0.0279 & $\mathrm{I}(1)$ \\
\hline CMB & -5.665135 & -3.595026 & 0.0005 & $\mathrm{I}(1)$ \\
\hline
\end{tabular}

Table 3. Unit Root Test Results (Augmented Dickey-Fuller Test Equation with trends and Intercept)

Results of the unit root test in table 3 reveals that the variables attained stationary at same order of integration. All the series are stationary after first difference (or order one). Based on the outcome, we employ the Error Correction Model technique to analyze our models.

\subsection{Correlation analysis}

\begin{tabular}{c|cccc}
\hline & InACN & InCMB & RTGR & WSGR \\
\hline INACN & 1 & & & \\
INCMB & -0.797859 & 1 & & \\
RTGR & -0.111723 & 0.172581 & 1 & \\
WSGR & -0.112429 & 0.178566 & 0.999598 & 1 \\
\hline \hline
\end{tabular}

Table 4. Correlation analysis results

The correlation analysis explains the nature of association among our respective variables of interest. The result reveals that commercial bank branches (CMB) were negatively associated with account ownership (ACN). The result further indicates that growth rate of the retail sub-sector (RTGR) and growth rate of the wholesale sub-sector (WSGR) were negatively related to account ownership (ACN) in a financial institution, but both were found to be positively associated with commercial bank branches $(\mathrm{CMB})$. 


\subsection{Regression estimates based on the error correction model (ECM)}

Regression result in table 5 shows that account ownership (ACN) had negative and non-significant influence on the growth rate of the retail sub-sector (RTGR) while commercial bank branches (CMB) exerted positive and significant effect on the growth rate of the retail sub-sector (RTGR). We observed that when ACN increased by one-unit, RTGR decreased by 44.96 units whereas one-unit change in CMB was associated with 166.75 units increase in RTGR. The result further reveals that our regressors jointly have significant influence on RTGR as indicated by the p-value of F-statistic $0.0000<0.05$. Moreover, the coefficient of determination (R-Squared) reveals that the independent variables accounted for about $79 \%$ of the variations in RTGR while the remaining $21 \%$ can be attributed to other variables not included in our model. The error correction term (speed of adjustment) is rightly signed and significant. This entails that deviations from long-run equilibrium path was being corrected at the speed of $92.14 \%$ on annual basis.

Table 6 presents the regression estimate of FI and the wholesale sub-sector growth rate. Similar to table 5, the result reveals that account ownership ( $\mathrm{ACN}$ ) had negative and non-significant effect on the growth rate of the wholesale sub-sector (WSGR) while commercial bank branches (CMB) was found to have positive and significant influence on the growth rate of the wholesale sub-sector (WSGR). It can be observed that one-unit increase in ACN led to about 41.50 units decline in WSGR. On the other hand, oneunit increase in CMB brought about 159.92 units increases in WSGR. The coefficient of determination shows that the independent variables explained about $78.95 \%$ of the variations in WSGR. The error correction dynamics reveals that errors or deviations from long-run equilibrium relationship were corrected at the speed of $92.49 \%$ annually. The overall regression was found to be significant as indicated by the p-value of F-statistic $0.0000<0.05$.

The regression results did not contradict the correlation results in table 4 where we observed that both the growth rate of the retail (RTGR) and the wholesale sub-sectors (WSGR) had strong positive association with commercial bank branches (CMB).

\begin{tabular}{ccccc}
\hline \multicolumn{5}{c}{ Dependent Variable: D(RTGR) } \\
\hline Variable & Coefficient & Std. Error & t-Statistic & Prob. \\
\hline C & 1.287986 & 0.716787 & 1.796887 & 0.0861 \\
D(ACN) & -44.95782 & 25.72684 & -1.747507 & 0.0945 \\
D(CMB) & 166.7508 & 53.15751 & 3.136919 & 0.0048 \\
ECT(-1) & -0.921409 & 0.204309 & -4.509873 & 0.0002 \\
\hline R-squared & 0.789456 & & & \\
Adjusted R-squared & 0.760745 & & & \\
Prob(F-statistic) & 0.000000 & & & \\
Durbin-Watson stat & 2.184239 & & & \\
\hline
\end{tabular}

Table 5. Regression Estimate (ECM Results): Financial inclusion and retail sub-sector growth (equation 1)

\begin{tabular}{lcccc}
\multicolumn{6}{l}{ Dependent Variable: $\mathrm{D}$ (WSGR) } \\
\hline Variable & Coefficient & Std. Error & t-Statistic & Prob. \\
\hline C & 1.212940 & 0.674558 & 1.798126 & 0.0859 \\
D(ACN) & -41.49075 & 24.21820 & -1.713206 & 0.1007 \\
D(CMB) & 159.9203 & 49.87980 & 3.206113 & 0.0041 \\
ECT(-1) & -0.924920 & 0.200802 & -4.606124 & 0.0001 \\
\hline R-squared & 0.789453 & & & \\
Adjusted R-squared & 0.760742 & & & \\
Prob(F-statistic) & 0.000000 & & & \\
Durbin-Watson stat & 2.168850 & & & \\
\hline
\end{tabular}

Table 6. Regression estimate (ECM Results): Financial inclusion and wholesale sub-sector growth (equation 2)

\subsection{Diagnostic Tests}

The validity of models used in this study is confirmed in figures 2 and 3 where the recursive estimate based on the cumulative sum (CUSUM) test shows that the respective models are well-specified and therefore, do not have any specification errors. The result shows that the blue line lies perfectly between the upper and lower bound red lines. It also confirmed that variables included in the models are 
normally distributed as shown in the Histogram normality tests in figures 4 and 5 below with p-values $(0.58>0.05)$ and $(0.56>0.05)$ greater that the $5 \%$ significant level.

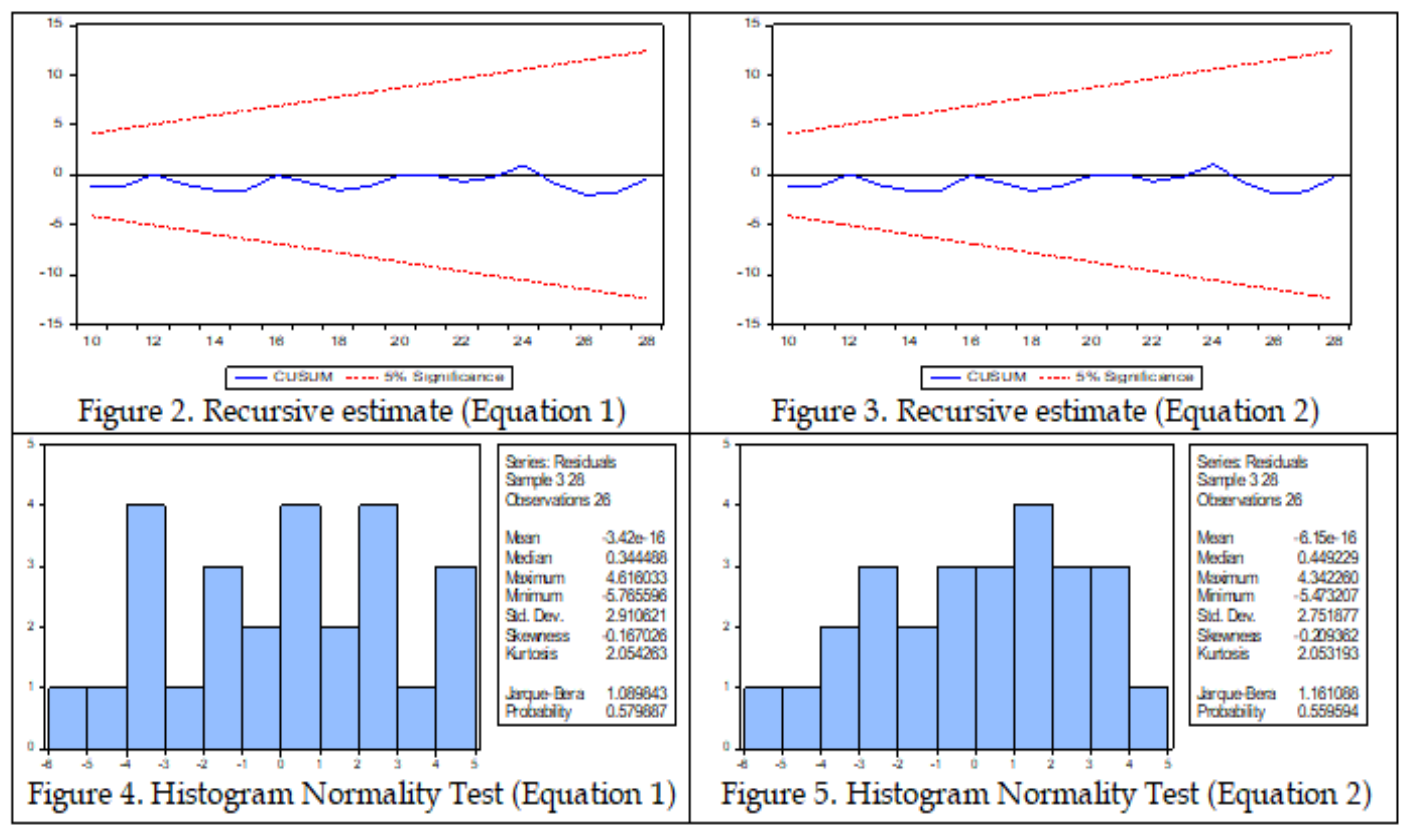

\section{Discussions and conclusions}

The correlation analysis explains the nature of association among our respective variables of interest. The result reveals that $\mathrm{CMB}$ were negatively associated with ACN. This may entail that bank branches per 100,000 adult population may not have translated into dragging unbanked population ages 15 and above into the financial system. The result further indicates that the RTGR and the WSGR were negatively related to $\mathrm{ACN}$, but both were found to be positively related to CMB. The established outcome between ACN and RTGR as well as ACN and WSGR suggests that ACN have not translated into EG in Nigeria particularly in the context of the retail and the wholesale sub-sectors contributions to GDP. On the other hand, the established outcome between CMB and RTGR as well as CMB and WSGR suggests that CMB have translated into EG in Nigeria, particularly in the context of the retail and the wholesale subsectors contributions to GDP.

Similarly, from the dynamic regression estimate carried out, the study reveals that ACN did not have significant influence on RTGR while CMB were found to have significant influence on the RTGR. This result did not differ relatively in the case of the wholesale sub-sector where the study shows that while ACN appear to have insignificant effect on the WSGR, CMB had significant positive effect on the WSGR. These regression results did not contradict the correlation results where we observed that both RTGR and the WSGR had strong positive association with CMB per cluster. This entails that CMB is a critical FI channel with potentials of driving the EG particularly in the context of the retail and the wholesale sub-sectors contributions to GDP. This finding is consistent with an earlier study carried out by Salman, Ayo-Oyebiyi and Emenike (2015) which found that mobile banking, banking services and banking penetration has significant positive effect on the growth and development of SMEs in Nigeria. Also, this finding clarifies and supports the perspective of Ibor, Offiong and Mendie (2017) that whereas FI positively and significantly impacts the operations and growth of SMEs, lack of nearness to the financial services access points can adversely affect the fast and effective access to financial services by SMEs in Nigeria. In other words, nearness of CMB has significant positive effect on entrepreneurial growth in Nigeria. There is, however, no evidence that ACN is relatively effective in generating much impact on the EG particularly in the context of the retail and the wholesale sub-sectors contributions to GDP within the coverage period. This research outcome brought to light the consequence of the research finding of Demirguc-Kunt and Klapper (2012) which revealed that less than a quarter of adults in Africa have an account with a formal financial institution. Also, that many adults in Africa use informal methods 
to save and borrow which has the implication of hindering capital accumulation, finance, entrepreneurial and economic growth.

Therefore, FI has a positive effect on entrepreneurial growth particularly in the context of the retail and the wholesale sub-sectors contributions to GDP. Though ACN is an aspect of FI, it has relatively less effect on EG compared with CMB which has significant positive effect on EG particularly in the context of the retail and the wholesale sub-sectors contributions to GDP within the coverage period. In other words, $\mathrm{CMB}$ is a crucial FI channel for effective EG in Nigeria.

\section{Limitations and direction for future research}

This paper focused on the effect of FI on EG in retail and wholesale sub-sectors in Nigeria using $\mathrm{ACN}$ and $\mathrm{CMB}$ as financial inclusion dimensions. For future studies, we suggest that the effect of FI on other economic sectors such as manufacturing, agriculture, forestry and services be studied in other to access the effect of inclusive finance on the growth rate of the sector's contributions to GDP for effective economic decision making.

\section{Recommendations}

Based on the findings of the study, we recommend that government should establish more commercial bank branches in all rural areas in Nigeria for easy access to official financial services by the unbanked entrepreneurs. Also, FI stakeholders should deepen efforts in encouraging account ownership in an official financial institution through improving on financial literacy of the vast unbanked populace so that formal financial system through capital accumulation can serve the needs of entrepreneurs for effective growth and contributions to GDP.

\section{Practical implications}

Commercial bank branches are critical FI channel with potentials of driving entrepreneurial growth particularly in the context of the retail and the wholesale sub-sectors contributions to GDP. Its establishment in all the rural areas in Nigeria will positively influence account ownership in a formal financial institution thereby achieving capital accumulation through which entrepreneurial growth and increased contributions to GDP will be met.

\section{References}

Ageme, A. E., Anisiuba, C. A., Alio F. C., Ezeaku, H. C., \& Onwumere, J. U. J. (2018). Empirical Assessment of Financial Inclusion on Poverty Reduction in Nigeria. European Journal of Economics, Finance and Administration, 99, 21-29.

Arogundade, R. (2019). Financial Inclusion: Nigerian Entrepreneurs Tap Growing Demand for POS Services. Frontline, June 23. Retrieved from https:/ / africanaentrepreneur.com/author/raheemat/

Babajide, A. A., Adegboye, F. B., \& Omankhanlen, A. E. (2015). Financial Inclusion and Economic Growth in Nigeria. International Journal of Economics and Financial Issues, 5(3), 629-637.

Central Bank of Nigeria (CBN) Statistical Bulletin, 2018.

Demirguc-Kunt, A. D., \& Klapper, L. (2012). Financial Inclusion in Africa: An Overview. The World Bank Development Research Group, Finance and Private Sector Development Team. Policy Research Working Paper 6088.

Gwalani, H., \& Parkhi, S. (2014). Financial Inclusion - Building a Success Model in the India Context. Procedia - Social and Behavioral Sciences, 133, 372-378.

Homaid, A. A., Minai, M. S., \& Al-Ansi, A. A. (2018). The Effect of Market and Entrepreneurial Orientation on the Performance of Microfinance Institutions: The Mediation Role of Learning Orientation in the Context of Yemen. Journal of Business and Retail Management Research, 12(3), 126-139.

Ibor, B. I., Offiong, A. I., \& Mendie, E. S. (2017). Financial Inclusion and Performance of Micro, Small and Medium Scale Enterprises in Nigeria. International Journal of Research - Granthaalayah, 5(3), 104-122.

Jiang, L., Tong, A., Hu Z., \& Wang, Y. (2019). The Impact of the Inclusive Financial Development Index on Farmer Entrepreneurship.nmPLoSONE, 14(5). doi: 10.1371/journal.pone.0216466

Kama, U., \& Adigun, M. (2013). "Financial Inclusion in Nigeria: Issues and Challenges." CBN Occasional Paper No. 45.

Lakuma, C. P., Marty, R., \& Muhumuza, F. (2019). Financial Inclusion and Micro, Small and Medium Entreprises (MSMEs) Growth in Uganda. Journal of Innovation and Entrepreneurship, 8(15). Retrieved from https://doi.org/10.1186/s13731-019-0110-2 
Nkwede, F. (2015). Financial Inclusion and Economic Growth in Africa: Insight from Nigeria. European Journal of Business and Management, 7(35), ISSN 2222-2839 [Online]. Retrieved from https:/ /www.semanticscholar.org

Oluwaseun, O. A. (2017). Financial Inclusion in Nigeria: The Challenges of Banks and Mobile Money Operators (MMOs). A paper presented at Bank of Morocco - CEMLA -IFC Satellite Seminar at the ISI World Statistics Congress on "Financial Inclusion" on 14th July 2017.

Okoye, L. U., Adetiloye, K. A., Erin, O., \& Modebe, N. J. (2017). Financial Inclusion as a Strategy for Enhanced Economic Growth and Development. Journal of Internet Banking and Commerce, 22(S8), 1-14.

Onaolapo, A. R. (2015). Effects of Financial Inclusion on the Economic Growth of Nigeria (1982-2012). International Journal of Business and Management Review, 3(8), 11-28.

Riwayati, H. E. (2017). Financial Inclusion of Business Players in Mediating the Success of Small and Medium Enterprises in Indonesia. International Journal of Economics and Financial Issues, 7(4), 623-627.

Salman, C. N., Ayo-Oyebiyi, G. T., \& Emenike, O. (2015). Influence of Financial Inclusion on Small and Medium Enterprises Growth and Development in Nigeria. International Journal in Management and Social Science, 3(4), 390-401.

Sarker, M. A. R., \& Ashrafi, D. M. (2018). The Relation between Internal Marketing and Employee Job Satisfaction: A Study from Retail Shops in Bangladesh. Journal of Business and Retail Management Research, 12(3), 149-159.

Scott, C. (2019). What is retail? What is wholesale? A guide for small business owners. Retrieved from https:/ / quickbooks.intuit.com/r/selling/retail-vs-wholesale-business-models-whats-best-business/

Terzi, N. (2015). Financial Inclusion and Turkey. Academic Journal of Interdisciplinary Studies, 4(1), 269-276.

World Bank's World Development Indicators. 